\title{
Standardising accessibility: Transferring knowledge to society
}

(iD) Anna Matamala

Universitat Autònoma de Barcelona

(D) Pilar Orero ${ }^{\bowtie}$

Universitat Autònoma de Barcelona

\section{Abstract}

Citation: Matamala, A., \& Orero, P. (2018). Standardising accessibility: transferring knowledge to society. Journal of Audiovisual Translation, 1(1), 139-154.

Editor(s): A. Jankowska \& E. Di Giovanni Received: December 22, 2018

Accepted: June 30, 2018

Published: November 15, 2018

Funding: This article is related to the research carried out in the NEA project, funded by the Spanish Ministry of Finance and Competitiveness (FFI201564038-P, MINECO/FEDER, UE) and in the European projects ImAC (GA: 761974) and EasyTV (GA: 761999). Both authors are members of TransMedia Catalonia (2017SGR113), research group funded by the Catalan government under the SGR funding scheme.

Copyright: (C2018 Matamala \& Orero. This is an open access article distributed under the terms of the Creative Commons Attribution License. This allows for unrestricted use, distribution, and reproduction in any medium, provided the original author and source are credited.
This article describes standardisation work in the field of media accessibility with a focus on the international standardisation bodies ISO (International Organization for Standardization) and ITU (International Telecommunication Union). It provides an overview of what standards are and how standardisation agencies work, with a focus on the technical procedures, types of documents and Code of Conduct to be followed. The specific tasks of working groups dealing with access services is presented and their main outputs in the form of standards are summarised. The article also discusses the main challenges researchers face when getting involved in standardisation work and the benefits of transferring into society and the industry through standardisation.

Key words: audiovisual translation, knowledge transfer, media accessibility, standardisation

$凶$ anna.matamala@uab.cat; https://orcid.org/0000-0002-1607-9011

凶pilar.orero@uab.cat; https://orcid.org/0000-0003-0269-1936 


\section{Introduction}

Standards can be viewed as a clear example of how knowledge generated in academia can interact with non-academic agents to produce a tangible product for the benefit of society. Standards are the bridge between academia and industry, a much sought after approach from the field of audiovisual translation. This article aims to shed light on what standards are, why they are needed and how researchers from the field of audiovisual translation and media accessibility can contribute to their development. Both authors are actively involved in standardisation work at the Spanish standardisation association UNE (Spanish Association for Standardization), and different international agencies such as ISO (International Organization for Standardization) and ITU (International Telecommunication Union). Their experiences will be used as examples to illustrate current work in the field.

The article starts with an overview of what standards are and a brief introduction to the main standardisation bodies (section 2). We then move on to describe how to get involved in standardisation using ISO work as a case study. An effort is made to describe the procedures for technical work and the Code of Conduct to be followed, as well as the types of documents that are produced. Section 3 illustrates the work done by a specific working group under ISO/IEC JTC1/SC35 in which both authors have been involved. After a short overview of the committee, the different access services that have been developed (or are in the process of being developed) are discussed in section 4. Section 5 presents another case study, by providing an overview of the work done at United Nations (UN) agency ITU in relation to access services in which one of the authors is involved. Section 6 discusses how the work at both institutions can converge and presents some of the challenges we faced as researchers when entering the world of standards. The article finishes with some general conclusions.

\section{Standards and standardisation bodies}

The Titanic is famous for having been sunk by an iceberg. It will always be remembered for the number of lives lost. This tragedy could have been avoided if the communication system had been standardised. Guglielmo Marconi invented the first system of wireless telegraphy, but it was one of many since each major country had a separate wireless company with its own frequency and system. In 1900 there were: two Morse codes in use, no laws concerning watch duty hours, and no standard set of equipment manufactured. The Titanic's silver lining is that it helped to push the drafting of the 1934 Communication Act where provisions for distress signals were set out. The Act required that frequencies be reserved for emergencies and that a licensed radio operator listen for such an emergency signal. Today this situation is difficult to imagine, since we all communicate through mobile telephones with different operating systems, having a contract with one of the many operators, in different regions of the world. Internet also runs universally thanks to the many communication protocols, and even hearing aids have a reserved frequency on 
the spectrum, so people wearing them do not receive aircraft or local radio frequencies. Almost anything can be standardised, and media accessibility is no exception (Looms, 2015). Wood (2011, p. 2) states that:

Technical standards apply in many fields, including the media industry. They evolve in response to new technologies that aim both to satisfy and to generate consumer demand. Standards can help to maximise choice and competition for goods and services, and they enhance access to goods and services of public value-including public service media. Other things being equal, the more widely a standard is used, the greater the overall benefit to consumers and citizens.

A standard is defined as follows by the European Telecommunication Standards Institute (ETSI, 2015, p. 215):

A document, established by consensus and approved by a recognised body, that provides for a common and repeated use, rules, guidelines or characteristics for activities or their result, aimed at the achievement of the optimum degree of order in a given context.

According to ISO (n.d.), standards "define essential requirements to make products and services that work". Even if we may not be aware of it, standards have an impact on our daily life and they guarantee that the products we use are safe, reliable and of good quality. Standards also ensure usability and predictability of such products and services. The need for this may be obvious in the case of electrical wiring, for a child's toy and for many technological components, as explained above, but many wonder about the role of standardisation in human-related factors. The answer is very straightforward as diverse users are consumers of the standardised products and their needs have to be taken into account.

Standards are different from legislation, and also from recommendations or guidelines. This is a common problem in academic papers on media accessibility where they are randomly quoted (Matamala \& Orero, 2013). Standards are developed and approved by recognised standardisation bodies. At the international level, the standardisation organisms are gathered under the umbrella of the World Standards Cooperation (WSC) and include ISO (International Standardisation Organisation), IEC (International Electrotechnical Commission) and the UN agency ITU (International Telecommunication Union), all based in Geneva (Switzerland).

ISO is an independent, non-governmental international organisation, with a membership of 162 national standards bodies. It was founded in 1946 and since then has published over 21,982 standards on various aspects of technology and manufacturing. IEC, founded in 1906, is a non-profit, quasi-governmental organisation that deals with standards related to electrical, electronic and related technologies. ITU, founded in 1865 as the International Telegraph Union, is the UN agency responsible for information and communication technologies, and mainly deals 
with the radio spectrum, satellites and communication systems. It has a group specialising in media accessibility named Intersector Rapporteur Group on Audiovisual Media, IRG-AVA for short. The IRGAVA studies topics related to audiovisual media accessibility, aims at developing draft recommendations for access systems that can be used for all media delivery systems, including broadcast, cable, Internet, and IPTV. The IRG also addresses matters contributing to the coordination of the standardisation work of the other two involved ITU groups: ITU-T (ITU Telecommunication Standardization Sector) and ITU-R (ITU Radiocommunication Sector). It also collaborates with standards organisations and other audiovisual media organisations such as forums, consortia, research institutes and academia. ITU is organised in six geographical regions and follows the UN M.49 (UN, n.d.) standard for area codes used by the United Nations for statistical purposes, which is developed and maintained by the United Nations Statistics Division'.

At the European level, the European Standards Organisations (ESOs) are CEN (European Committee for Standardisation), CENELEC (European Committee for Electrotechnical Standardisation) and ETSI (European Telecommunication Standards Institute), all three of them officially recognised by the European Union and by the European Free Trade Association. The CEN agency, founded in 1961, is an association in which the national standardisation bodies of 34 European countries come together, and it supports standardisation in many fields and sectors, from air and space to transport, packaging or health and safety. CENELEC is a non-profit technical organisation set up under Belgian law in 1973 that standardises in the field of electrotechnical engineering. ETSI is a not-for-profit organisation with more than 800 member organisations worldwide that produces standards for information and communications technology (ICT).

The European Union promotes an active standardisation policy because standards are viewed as a means to improve regulation and as a way to enhance European industry competitiveness. As explained on a dedicated website on standardisation policy, standards at European level "support market-based competition and help ensure the interoperability of complementary products and services. They reduce costs, improve safety, and enhance competition" (European Commission, n.d.). The Joint Initiative on Standardisation (European Commission, 2016) is a good example of such interest, as it sets out a shared vision for European standardisation. A set of actions is being drafted based on three priorities: the first is awareness, education and understanding of the European standardisation system; the second is coordination, cooperation, transparency and inclusiveness, and the third is competitiveness and international dimension.

Standards are a pre-requisite for laws. Unless there is a standard to refer to, a law will be meaningless, and this has a direct implication in media accessibility. In Europe, following the Audiovisual Media Service Directive (AVMSD), all countries have the obligation to pass legislation regarding accessibility services offered in public broadcasting". Since there is no EU standard for subtitling, sign language interpretation or audio description, the AVMSD could only measure the quantity of programmes to be broadcasted with each service. An exception is the Spanish Standard on subtitling (UNE135020), audio description (UNE135010), and easy reading (UNE/PNE153101 EX) issued by UNE (formerly 
AENOR). To reflect on the EU diversity, each EU country has its standardisation agency: Association Française de Normalisation (AFNOR) in France, British Standards Institution (BSI) in the UK and National Standards Authority of Ireland (NSAI) in Ireland, just to mention a few.

Apart from standardisation bodies, other stakeholders interact in media accessibility. Each country has also its own independent media regulating body for audiovisuals under the European Regulators Group for Audiovisual Media Service (ERGA). The latter is responsible for advising the Commission on the implementation of AVMSD, and in some cases like Office of Communications (Ofcom, 2018) in the UK, goes beyond checking the quantity of accessibility services and also seeks to regulate quality. The Ofcom guidelines for accessibility services are perhaps the most widely quoted document in academic accessibility services publications, although they only apply in the UK. Commercial players also have in-house guidelines or recommendations that are seldom made public and tend to be loosely based on a national standard, if available. Figure 1 illustrates the four key players interacting in media accessibility standardisation.

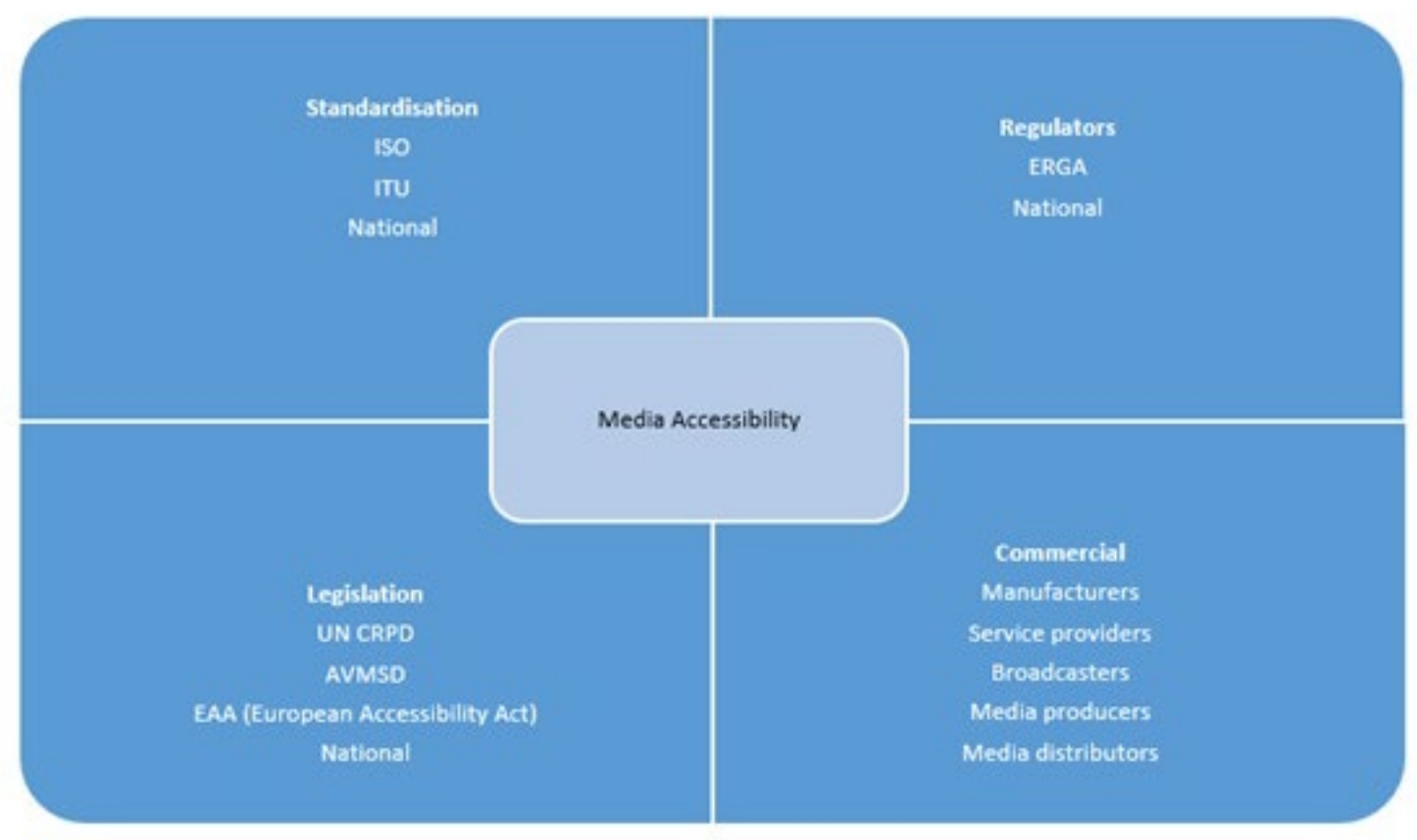

Figure 1. Player interaction in media accessibility standardisation

Some agencies may decide to work together: ISO and IEC form the specialised system for worldwide standardisation. National bodies that are members of ISO or IEC participate in the development of international standards through technical committees established by the respective organization to deal with particular fields of technical activity. ISO and IEC technical committees collaborate in fields of mutual interest. Other international organisations, in liaison with ISO and IEC, also take part in the work. 
In the field of information technology, ISO and IEC have established a Joint Technical Committee 1: ISO/IEC JTC 1. This committee has responsibility for standardisation in the area of information technology. Within JTC 1 are a number of technical committees of which Subcommittee 35 (SC35) is the lead subcommittee on User Interface Component accessibility. ISO/IEC JTC1/SC35 have now joined ITU IRG-AVA and will, in the future, endorse joint international standards on accessibility (https://www.worldstandardscooperation.org/accessibility/).

\section{An example at ISO: a subcommittee on user interfaces}

This section describes how ISO is structured, the procedures that are followed for technical work and the Code of Conduct that is followed by all participants. The types of deliverables and stages will be clarified, before describing in detail the work of this specific committee and how this relates to accessibility in the next section.

\section{a) ISO structure}

The main bodies in ISO are the General Assembly, the ISO Council (which takes care of most governance issues) and the Technical Management Board, which is responsible for the technical committees.

The technical committees are made up of ISO national members bodies, which can be participating (P-member) or observing (O-member) members. Technical committees, which can have subcommittees (SC) and working groups (WG), are led by a chair. For instance, ISO/IEC JTC1 Information Technology has $34 \mathrm{P}$-members and 63 O-members. It is structured in various subcommittees and working groups. For example, subcommittee 35 deals with user interfaces. It has 17 P-members and 17 O-members, and 10 working groups. WG 6 deals specifically with user interface accessibility, and it is where documents on access services have been developed.

In technical committees, participants take different roles: there is a committee chair whose role is to help the committee reach internationally accepted agreements. At a working group level there is a convenor who leads the work and also tries to work towards consensus. Both delegates and experts take part in meetings: delegates, with a head of delegation, represent a national body and are accredited by such. Technical committees also have liaisons with various organisations and many ISO members belong to other organisations and help to coordinate.

\section{b) Procedures for technical work and Code of Conduct}

As explained by the ISO/IEC Directives, ISO's technical work is based on five main concepts: market relevance; application of modern technology and programme management; consensus; discipline; and cost-effectiveness. Although unanimity is not required, substantial objections 
must be overcome during the process of standard creation, in which discipline to meet deadlines and to respect national positions and to report to national mirror committees is needed. In fact, all ISO participants need to follow a Code of Conduct (ISO 2016a), which states that they should:

- work for the benefit of the international community

- uphold consensus and governance

- agree to a clear purpose and scope

- participate actively and manage effective representation

- escalate and resolve disputes

- behave ethically

- respect others in meetings.

\section{c) Types of deliverables and stages}

The main deliverable in ISO standardisation process are International Standards (IS). They can refer to products, but also to testing methods, codes of practice, management system standards, among others. When a product is still under technical development, a Technical Specification (TS) is pushed forward, in the hope that it will become an IS in the future. TS are often released for immediate use and to get feedback. Other types of deliverables are: Technical Reports (TR), which contain different types of information (for instance, a state of the art or the results of a survey); Publicly Available Specification (PAS), which are also published when there is an urgent market need for immediate use and in order to get feedback, and International Workshop Agreements (IWA), which are documents developed outside the usual system (ISO, 2016b, pp. 23-24).

When developing a standard, as explained in ISO (2016b, pp. 26-27), the first step is the proposal to work on a new item (NWIP, New Work Item Proposal). After this stage, the preparatory stage begins and a Working Draft (WD) is generally prepared, followed by successive versions in which expert consensus is built. An additional stage in which a Committee Draft (CD) is circulated to the members of the committee, can also take place, and successive CDs can be circulated. When there is consensus, the Draft International Standard (DIS) enters the enquiry stage and all ISO members have three months to vote and send comments. It will be approved if two-thirds of the P-members are in favour, and not more than one-quarter of the total number of votes is negative. If the DIS is approved, it can be published directly, but there is also the option to include another stage, namely the approval of the Final Draft of the International Standard (FDIS).

The development of a project has different possible timeframes, ranging from 24 months to publication for the fastest ones, up to 48 months to publication in the enlarged standards development track, the default being 36 months to publication (and 24 months to produce 
the DIS). To search for standards or publications issued by ISO, there is a dedicated search engine on the ISO website.

\section{d) Subcommittee overview}

ISO/IEC JTC $1 /$ SC 35 is a subcommittee currently chaired by Khalid Choukri, with a secretariat led by the French agency AFNOR. Created in 1998, as explained on its website, it deals with standardisation "in the field of user-system interfaces in information and communication technology (ICT) environments and support for these interfaces to serve all users, including people having accessibility or other specific needs, with a priority of meeting the JTC1 requirements for cultural and linguistic adaptability" (ISO, n.d.). So far it has published 69 ISO standards and it has 19 standards under development, with 17 P-members and 17 O-members. It meets for a week twice a year, and it is structured in various working groups. WG6 specifically works on User interfaces accessibility, and it is within this WG where various documents concerning access services have been developed.

\section{Access services standards}

This section will focus on three standards developed within WG6 which are directly related to access services. Since 2014, the authors of this paper have been involved in WG6 at ISO/IEC JTC1/SC35 and have either been co-editors or experts in the development of the following standards. It must be emphasised that we got involved through the Spanish mirror committee. ISO members are national agencies. Participation in ISO has to be done through the national standardisation agency, in our case UNE and the specific committee we belong to (CTN 133).

The following standards are all part of the same series and refer to three access services: audio description, audio subtitling and subtitling. Other standards developed within the WG in relation to accessibility can be found on the ISO website.

a) ISO/IEC TS 20071-21: 2015 Information technology - User interface component accessibility Part 21: Guidance on audio descriptions

Published in 2015 (ISO, 2015), this technical specification is 24 pages long and was led by Canadian experts, with input from members of the WG. The document describes how different types of audio description are created, namely live audio descriptions and recorded audio descriptions. The guideline touches upon various aspects such as how to develop an audio description, the styles of narration, the levels of importance, and how to describe relevant sounds and text on screen. Specific guidance on how to describe objects, characters, spatio-temporal settings and relationships is proposed. This standard includes a wide array of examples that clarify its recommendations. 
b) ISO/IEC TS 20071-25: 2017 Information technology - User interface component accessibility. Part 25: Guidance on the audio presentation of text in videos, including captions, subtitles and other on-screen text

This is a 12-page technical specification (ISO, 2017) led by Ester Hedberg and Anna Matamala, with input from multiple experts. The proposal was initially suggested at a meeting in Barcelona in 2014. In 2015, a presentation was made in Denmark and consensus on the interest of the proposal and its scope was reached. After two years of discussions and successive versions, the document was published in February 2017.This document provides guidance on how captions/subtitles and other on-screen text can be transmitted auditorily. In fact, it is not limited to captions/subtitles but can also be applied to other types of video texts, as described in section 4.2 of the specification.

It is interesting to note that the document does not include the term audio subtitles in the title, although in section 4.1.1 it acknowledges different terms such as audio subtitles, spoken subtitles, spoken captions, audio captions. This was the result of lengthy discussions during its development. First of all, we wanted the document to refer not only to captions or subtitles on screen but also to any other type of text that appeared in video content. Moreover, as this document is related to Part 23 (see next sub-section), it was agreed that a parallel structure referring to the type of presentation (audio/visual) should be followed in the title. This is why Part 25 refers to audio presentation (in this case of text on screen) whilst Part 23 refers to visual presentation (in this case of audio information).

The document gives recommendations on how to create and deliver audio presentations of text in videos, and refers to specific aspects such as synchronisation, establishing levels of importance or identifying the audio presentation of text in videos, among other aspects.

\section{c) ISO/IEC DIS 20071-23: 2018 Information technology - User interface component accessibility -} Part 23: Guidance on the visual presentation of audio information (including captions and subtitles)

This International Standard (ISO, 2018) is in the final stages of its development and it has been led by Japanese and Canadian experts. The different approaches to subtitling and/or captioning, including the definition of such terms, has been controversial but consensus has been reached to put forward a document that deals with various aspects of subtitling. It recognises the different types of presentations, access and display, and discusses the question of how to prioritise information. It makes a distinction between predictable and unpredictable audio content, which has an impact on what users can expect. The document refers to issues such as quality, end user involvement and visual design. It also defines the correspondence of captions/subtitles with the audio information of the content, and refers to synchronisation aspects. Special emphasis 
is laid on how to subtitle speech and non-speech information such as sound effects, music, emotions and silence. It also describes the different means of identifying speakers.

\section{An example: ITU}

The International Telecommunication Union - Telecommunication Standardization Sector (ITU-T) acts as a forum where governments and the private sector develop standards for global telecommunication networks and services. It is one of the Sectors of the International Telecommunication Union (ITU), an international specialised agency within the UN system. The main products of ITU are technical papers and recommendations defining how telecommunication networks operate and interoperate. Recommendations have non-mandatory status until they are adopted in national laws. The level of compliance is nonetheless high due to international applicability and the high quality guaranteed by ITU secretariat and members from the world's foremost ICT companies and global administrations.

In ITU-T there are study groups meeting twice a year where work on recommendations is carried out. New recommendations may be created in two ways. While working on one recommendation, the need for further information may be requested: this is called a contribution. One or more members are asked to write and present contributions for the next meeting. A contribution may become in itself a new working item, and eventually a recommendation. Considering there are thousands of recommendations, ITU has created an application where recommendations and other documents such as questions, reports or resolutions can be searched: it is the BR Document Search (https://extranet.itu.int/brdocsearch).

The procedure to generate a new proposal requires a specific document to be filled in. If the recommendation proposal is accepted, the editor will work on the text of the document, first presenting a structure that will be developed with contributions from other partners over the next two to three years.

The following documents related to accessibility have been published at ITU:

\section{a) 2006 - FSTP- TACL - Telecommunications Accessibility Checklist}

This is a basic but fundamental publication (ITU-T, 2006). It provides a list with the basic structure to address various aspects of accessibility. Good accessibility requires that most of these aspects are open for more than one method of user interaction. The primary intention of the checklist is to provide a structured set of reminders for standards writers during the process of creating standards in the ICT area. Whenever a standardisation work item is created, or its documents and progress evaluated, the checklist should be consulted. For many points, an example is provided. The checklist item is not limited to the examples. It is structured 
by the following topics: control devices through a user interface, control of services, media transport, media entry by the user, media presentation to the user, invocation of media translating services, user profile management, and user profile usage.

\section{b) 2015-FSTP-ACC-RemPart- Guidelines for supporting remote participation in meetings for all}

This document (ITU-T, 2015a) outlines the requirements for ensuring that meetings are accessible to remote participants, including those with disabilities and those using assistive technologies. Remote participants are those who are not present at the physical location of the meeting but who are taking part via audiovisual communication. This can be done via the Internet and also by using traditional telephone conferencing methods. The requirements do not cover the following aspects of meetings access, although the importance of addressing these is stated in the section 'Outline checklist of other issues, not covered in detail': physical meetings attendance, local meetings access, communication and working procedures between meetings, accessibility of public and working documents (other than those required for accessing meetings or used within meetings), and choice between open standards and proprietary solutions.

\section{c) 2015 - FSTP-AM - Guidelines for accessible meetings}

This technical paper (ITU-T, 2015b) provides guidelines for the organisation of meetings that facilitate the inclusion of persons with disabilities and the elderly, to eliminate all barriers to participation. It has been based on various guidelines and best practices, in particular the compilation by the Internet Government Forum (IGF) Dynamic Coalition on Accessibility and Disability (DCAD). Staff involved in the organisation and running of meetings need to understand certain procedures, and include the identified requirements as mandatory in host agreements. These procedures and requirements are ascertained in this document.

\section{d) 2016 - FSTP-UMAA - Use cases for assisting persons with disabilities using mobile applications}

This Technical Paper (ITU-T, 2016) illustrates the use cases for assisting persons with disabilities using mobile phones. The idea starts from using the mobile phone as a digital assistant for the person with disability (PwD). These applications are designed to perform specific function(s) that are essential for persons with disabilities in their daily activities, spanning from reading text to walking on the road alone or identifying colour and money.

ITU also publishes longer documents, or reports, such as Making television accessible (ITU, 2011), which provides a checklist for implementing accessible television and, or the e-Accessibility Policy Toolkit for Persons with Disabilities (ITU, n.d.), which focuses more specifically on the Convention on Rights of Persons with Disability (CRPD) provisions on accessibility to information and communication technologies. 


\section{From research to standardisation: challenges}

Taking part in standardisation is seen as a relevant task in many funded projects, since it is considered part of a dissemination activity. It is also considered as project resilience, or what will remain after completion. This is a critical issue since many funded projects have excellent results which are never taken over by the industry, or exploited further beyond the life of the project. The project may have a finishing date, but if its results are used to produce standards, the project outcome will stay alive for years to come.

Work in standardisation is different from research and it does not come without challenges (Xie, Hall, McCarthy, Skitmoer \& Shen, 2016). When working on access services, one of the recurrent issues which is hard to find consensus on is the terminology. Each area has its own usages of words such as captions or subtitles, of descriptive video or audio description, so agreeing on a common definition is not an easy job. The same applies to words such as spoken subtitles, audio subtitles or audio text, which are used with similar meanings by different stakeholders. Another issue is related to English, nowadays used as lingua franca, for drafting recommendations and standards. How the terminology chosen in English will impact on the translation to the vernacular(s) of each country is a key issue since it can be the case that two terms in English can only be translated by one term in the target language (caption and subtitle are translated into subtítol in Catalan).

Industrial partners are very active in standardisation agencies. Obtaining proprietary solutions at a global level through standards is a great commercial opportunity, but on such occasions lobbying and agreements are taken at a different level. Reaching consensus at the national and international level with different types of stakeholders, not only academic partners but also industry and end users from different backgrounds, is challenging but at the same time fruitful because it enriches the discussions with myriad new perspectives.

Another oft-mentioned concern is whether academics should contribute with their own work to standards that are not free, as is the case when articles are given for free to publishing houses who in turn charge. Academic research is often paid by public funding which benefits publishing houses, and research results are not always freely available to the society which has paid for them. It seems research results and data, such as standardisation, may have an unavoidable price tag attached to them. It remains to be seen whether the active open access movements in academic publication will also have an impact on other fields such as standardisation, and open and free access to knowledge generated by public funding will be generalised.

In the case of accessibility standardisation, and following the UN CRPD (2006) "nothing about us without us", end users should have a voice in standardisation agencies. It is of the utmost importance that the end user's voice is heard, and that research supports the statements that are made. The TransMedia Catalonia research group, for instance, specialises in user testing in access service research (Orero and Matamala, 2016; Matamala et al., 2018) and tries to transfer this knowledge 
to standardisation. Its ultimate aim is to provide a better experience to diverse audiences. Associations such as ANEC (European Association for the Co-ordination of Consumer Representation in Standardisation) indicate that in some standardisation agencies the "societal interest may not be naturally represented" (European Association for the Co-ordination of Consumer Representation in Standardisation, n.d.) and consumers' voice is weak or fragmented, hence the need for user-centric research to be transferred into standards (Matamala and Orero, 2013).

Another important issue is how different agencies working on standards in related topics can converge and produce a unified standard. As an example of good practice, ISO and ITU are in the process of cooperating in access services standards. In the ISO/IEC JTC1 SC35 meeting in Paris in July 2017, a representative from ISO was invited to discuss joint collaboration between both standardisation bodies. An obvious positive result was that the next meeting of the ISO subcommittee took place at the ITU headquarters in Geneva six months later, and experts shared information on their respective work. A successful output of this meeting was the willingness to create so-called twin texts and initiate a revision of the three ISO standards presented in this article, and a resolution to start a collaboration between ISO/IEC JTC1 SC35 and ITU-T SG16.

Finally, more research is needed on how standards influence the development of access services. It seems logical to think that when a country wants to implement an access service, it will look at previous experiences in other countries. It is also advisable to consult international standards to set quality procedures and measures, as whole. In the end, more research is still needed in order to evaluate the actual usage and implementation of access service standards worldwide.

\section{Conclusions}

As academics working for standardisation agencies, the enterprise may be daunting since it encounters challenges on many levels. Collaboration is not paid, and time and travelling costs must be met by the researcher. Research impact these days is measured by publishing in indexed journals. However, standards are anonymous and while being an editor may be taxing, any collaboration towards writing a standard is not academically recognised.

On the other hand, working at a global level in a mixed group formed by industry and academia offers the opportunity to disseminate research results beyond the established research field and geographical region. This is a pertinent issue when dealing with media accessibility, since it is language dependent. Contact with industrial partners allows researchers to focus research lines and keep ahead of research trends, since academia is epigonic to industry and market needs by definition (Iwanaka, 2009). Moreover, researchers working in standardisation groups develop new skills, namely the ability to negotiate, which is very useful when having to deal with university officials, who are these days the gatekeepers of funding and research policies. 
The field of audiovisual translation and media accessibility has aimed to bridge the gap between industry and academia. Industry participates in joint conferences but rarely reads academic journals. Industry follows standards, and if academics aim at industry following their findings, this happens through standardisation. The European Association for Studies in Screen Translation (ESIST) was created, as early as 1995, with its goal "to facilitate the exchange of information and to promote professional standards in the training and practice of screen translation". In a way standardisation was identified at the heart of audiovisual translation, but still participation from academia is not very active.

\section{Biographical notes}

Anna Matamala, PhD, is Associate Professor at UAB (Barcelona). Currently leading TransMedia Catalonia, she has participated in and led projects on audiovisual translation and media accessibility. She has taken an active role in the organisation of scientific events (M4ALL, ARSAD), and has published in journals such as Meta, Translator, Perspectives, Babel, Translation Studies. She is involved in standardisation work at ISO and UNE. Co-founder of MAP (Media Accessibility Platform). Website: http://gent.uab.cat/amatamala

Pilar Orero, PhD, teaches at the Universitat Autònoma de Barcelona (Spain). Member of the TransMedia Catalonia research group. Recent publications include two co-edited books on audio description (with Maszerowska and Matamala, 2014, Benjamins; with Matamala, 2016, Palgrave Macmillan). Pilar Orero participates in ITU IRG-AVA and is a member of ISO/IEC JTC1/SC35 and Spanish UNE working group on accessibility. Leader of EU projects HBB4ALL, ACT, UMAQ, and partner in EasyTV and ImAC (2017-2021). She is an active external evaluator for many worldwide national agencies (South Africa, Australia, Lithuania, Belgium, US, UK, etc.). Co-founder of MAP (Media Accessibility Platform).

\section{References}

European Association for the Co-ordination of Consumer Representation in Standardisation (n.d.).

The Standardisation Regulation. Retrieved from https://www.anec.eu/about-anec/thestandardisation-regulation

European Telecommunication Standards Institute (2015). ETSI Drafting Rules. Retrieved from https://portal.etsi.org/Portals/0/TBpages/edithelp/Docs/38 directives feb 2018 part2\%2 $\underline{\text { O(EDRs).pdf }}$

European Commission (n.d.). Standardisation policy. Retrieved from https://ec.europa.eu/growth/single-market/european-standards/policy en

European Commission (2016). Joint initiative on standardisation: Responding to a changing marketplace. Retrieved from http://ec.europa.eu/growth/content/joint-initiativestandardisation-responding-changing-marketplace-0 en 
International Organization for Standardization (n.d.). Standards in action. Retrieved from https://www.iso.org/standards-in-action.html

International Organization for Standardization (n.d.). User interfaces (ISO/IEC JTC 1/SC 35). Retrieved from https://www.iso.org/committee/45382.html

International Organization for Standardizarion (2016a). ISO code of conduct for technical work. Retrieved from https://www.iso.org/files/live/sites/isoorg/files/publications/en/pub100397.pdf

International Organization for Standardization (2016b). My ISO job. Retrieved from https://www.iso.org/files/live/sites/isoorg/files/archive/pdf/en/my iso job.pdf

International Organization for Standardization (2018). Information technology - user interface component accessibility - Part 23: Guidance on the visual presentation of audio information (including captions and subtitles) (ISO/IEC DIS 20071-23: 2018). Retrieved from https://www.iso.org/standard/70722.html

International Organization for Standardization (2015). Information technology - user interface component accessibility - Part 21: Guidance on audio descriptions (ISO/IEC TS 2007121:2015). Retrieved from https://www.iso.org/standard/63061.html

International Organization for Standardization (2017). Information technology - user interface component accessibility. Part 25: Guidance on the audio presentation of text in videos, including captions, subtitles and other on-screen text (ISO/IEC TS 20071-25:2017). Retrieved from https://www.iso.org/standard/69060.html

International Communication Union (n.d.). E-accessibility policy toolkit for persons with disabilities. Retrieved from http://www.e-accessibilitytoolkit.org/

International Communication Union (2011). Making television accessible. Retrieved from http://staging.itu.int/en/ITU-D/Digital-Inclusion/Persons-withDisabilities/Documents/Making TV Accessible-English.pdf

ITU Telecommunication Standardization Sector (2006). FSTP-TACL telecommunications accessibility checklist. Technical Paper. Retrieved from https://www.itu.int/dms pub/itu-t/opb/tut/TTUT-FSTP-2006-TACL-MSW-E.doc

ITU Telecommunication Standardization Sector (2015a). FSTP.ACC-RemPart - guidelines for supporting remote participation in meetings for all. Retrieved from https://www.itu.int/dms pub/itu-t/opb/tut/T-TUT-FSTP-2015-ACC-PDF-E.pdf

ITU Telecommunication Standardization Sector (2015b). FSTP-AM - guidelines for accessible meetings. Retrieved from https://www.itu.int/dms pub/itu-t/opb/tut/T-TUT-FSTP-2015AM-PDF-E.pdf

ITU Telecommunication Standardization Sector (2016). FSTP-UMAA - use cases for assisting persons with disabilities using mobile applications. Retrieved from https://www.itu.int/dms pub/itu-t/opb/tut/T-TUT-FSTP-2016-UMAA-PDF-E.pdf

Iwanaka, T. (2009). Technical innovation, standardization and skill qualification for pediatric minimally invasive surgery in Japan. Journal of Pediatric Surgery, 44(1), 36-42. 
Looms, P.O. (2015). Standardization of audiovisual media accessibility. In P. Biswas, C. Duarte, P. Langdon \& L. Almeida (Eds.), A multimodal end-2-end approach to accessible computing (pp. 317-334). London, UK: Springer.

Matamala, A. \& Orero, P. (2013). Standardising audio description. Italian Journal of Special Education for Inclusion, 1, 149-155.

Matamala, A., Orero, P., Rovira-Esteva, S., Casas-Tost, H., Morales, L.F., Soler-Vilageliu, O., Agulló, B., Fidyka, A., Segura, D., \& Tor-Carroggio, I. (2018). User-centric approaches in access services evaluation: profiling the end user. In I. Schuurman, L. Sevens, V. Yaneva \& J. O'Flaherty (Eds.), ISI-NLP2 (Improving Social Inclusion using NLP: Tools, Methods, Resources). 2018 Workshop proceedings. Proceedings of the eleventh international conference on language resources evaluation (LREC 2018) (pp. 1-7). Paris, France: ELRA.

Office of Communications (2018). Choosing the best broadband, mobile and landline provider. Retrieved from https://www.ofcom.org.uk/ data/assets/pdf file/0023/113639/fullreport.pdf

Orero, P. \& Matamala, A. (2016). User-centric audio description: a topsy-turvy research approach. In A. Manco \& A. Mancini (Eds.), Scrittura breve: segni, testi e contesti [Short writing: signs, texts and contexts] (pp. 356-387). Naples, Italy: Università degli Studi di Napoli.

United Nations. (n.d.). Standard country or area codes for statistical use. https://unstats.un.org/unsd/methodology/m49/

United Nations. (2006). The convention on the rights of persons with disabilities and its optional protocol (A/RES/61/106). Retrieved from https://www.un.org/development/desa/disabilities/convention-on-the-rights-of-personswith-disabilities.html

Wood, D. (2011). Mapping digital media: Technical standards in terrestrial television. Retrieved from https://www.opensocietyfoundations.org/sites/default/files/mapping-digital-mediatechnical-standards-20110819.pdf

Xie, X., Hall, J. McCarthy, I. Skitmore, M., \& Shen, L. (2016). Standardization efforts: The relationship between knowledge dimensions, search processes and innovation outcomes. Technovation, 48-49, 69-78.

\footnotetext{
' Based on the UN M.49, countries are classified according to macro geographical regions and sub-regions, and selected economic and other groupings, see: http://unstats.un.org/unsd/methods/m49/m49regin.htm

"To consult AVMSD transposed to each EU country, please see: http://avmsd.obs.coe.int/cgi-bin/search.php
} 